\title{
Mechanisms of Successful Amoxicillin Prophylaxis of Experimental Endocarditis Due to Streptococcus intermedius
}

\author{
P. Moreillon, P. Francioli, D. Overholser, P. Meylan, \\ and M. P. Glauser
}

From the Division of Infectious Diseases, Department of Internal Medicine, Centre Hospitalier Universitaire Vaudois, Lausanne, Switzerland

\begin{abstract}
Prophylaxis with amoxicillin $(40 \mathrm{mg} / \mathrm{kg}$ ) was studied in rats with aortic valve vegetations. Bacteria on the valves were quantitated early ( $10 \mathrm{~min}$ to $6 \mathrm{hr}$ ) and late (three days) after intravenous challenge with tolerant Streptococcus intermedius. Amoxicillin reduced by $40 \%$ the number of bacteria per valve $10 \mathrm{~min}$ after intravenous challenge with $10^{5} \mathrm{~S}$. intermedius $(P<.05)$ and by $74 \%$ the incidence of endocarditis three days thereafter $(P<.0001)$. Bacterial multiplication started $2 \mathrm{hr}$ after challenge in control rats, whereas bacteria disappeared in $6 \mathrm{hr}$ in amoxicillin-treated rats. Intravenous penicillinase $30 \mathrm{~min}$ after challenge abolished successful amoxicillin prophylaxis, a result demonstrating the necessity of prolonged growth inhibition for protection. Growth inhibition for $18 \mathrm{hr}$ (two subsequent amoxicillin doses) was necessary for protection after intravenous challenge with $10^{5} \mathrm{~S}$. intermedius. Thus, in the absence of bacterial killing, inhibition of valvular colonization by amoxicillin was not as important a mechanism of endocarditis prophylaxis as was prolonged inhibition of bacterial growth, which allowed adherent bacteria to be cleared from the valves.
\end{abstract}

Successful antibiotic prophylaxis of experimental bacterial endocarditis can be achieved by mechanisms other than antibiotic bactericidal activity [1-3]. Several studies in which viable Streptococcus sanguis organisms were exposed to nonbactericidal concentrations of vancomycin or amoxicillin showed that the exposed bacteria were less able than the controls to stick to platelet-fibrin matrices in vitro and to induce endocarditis in animals with catheterinduced vegetations. These observations suggested that in the absence of bacterial killing, antibiotics might prevent endocarditis by reducing the adherence of circulating microorganisms to the damaged valves [1-3]. More recently, Lowy et al. [4], using a strain of $S$. sanguis pretreated with an inhibitory concentration of penicillin, observed both a decreased adherence of the bacteria to platelet-fibrin matrices

Received for publication 27 February 1986, and in revised form 2 June 1986.

Part of this work has been published in abstract form (no. 336) in the Proceedings and Abstracts of the 24th Interscience Conference on Antimicrobial Agents and Chemotherapy.

This work was supported by grant 3.847 .083 from the Swiss National Foundation for Scientific Research.

We thank José Entenza and Marlyse Giddey for technical assistance and Sylviane Bovey for typing the manuscript.

Please address requests for reprints to Dr. M. P. Glauser, Division of Infectious Diseases, Department of Internal Medicine, Centre Hospitalier Universitaire Vaudois, 1011 Lausanne, Switzerland. in vitro and a slight but significant reduction in their ability to colonize damaged aortic valves of rabbits in vivo. However, despite these observations, all the rabbits injected with the penicillin-pretreated bacteria had developed endocarditis when killed $24 \mathrm{hr}$ after bacterial challenge, a result raising the question of whether inhibition of bacterial adherence was actually an efficient mechanism of endocarditis prophylaxis. Moreover, nonbactericidal concentrations of antibiotics that were successful in the prophylaxis of endocarditis may have had various effects on bacteria such as growth inhibition and enhanced susceptibility to ingestion and killing by phagocytes [5], effects not ruled out by the above studies.

To elucidate further the mechanisms of successful prophylaxis of bacterial endocarditis in the absence of bacterial killing, we performed experiments aimed at determining in vivo the role of the reduction of valvular colonization due to the inhibition of bacterial adherence in the successful prophylaxis of bacterial endocarditis.

\section{Materials and Methods}

Microorganism. Streptococcus intermedius, also referred to as $S$. sanguis in some experiments [1], was originally isolated from a patient with endocarditis and has previously been used in production of experimental endocarditis in rabbits $[6]$ and rats $[1,3$, 
7]. The MIC and MBC of amoxicillin for this strain have been shown to be 0.125 and $>128 \mu \mathrm{g} / \mathrm{ml}$, respectively, resulting in a $\mathrm{MBC} / \mathrm{MIC}$ ratio of $>1,024$ [3].

It was previously established by time-killing curves (with an inoculum of $10^{6}$ bacteria and a concentration of $25 \mu \mathrm{g}$ of amoxicillin $/ \mathrm{ml}$ ) that no significant killing of this strain occurred during the first $6 \mathrm{hr}$ of incubation and that only a marginal decrease in the number of cfu occurred after $24 \mathrm{hr}$ [3]. Similar observations were made with an inoculum of $10^{3}$ and $10^{2}$ bacteria (authors' unpublished observation). The concentration of $25 \mu \mathrm{g}$ of amoxicillin $/ \mathrm{ml}$ was used in those experiments because it is similar to the serum levels achieved in rats $30 \mathrm{~min}$ after iv administration of $40 \mathrm{mg} / \mathrm{kg}$ and in humans $2 \mathrm{hrs}$ after an oral dose of $3 \mathrm{~g}$.

Serum inhibitory and bactericidal titers. The serum inhibitory and bactericidal titers against $S$. intermedius $30 \mathrm{~min}$ and 2,4 , and $6 \mathrm{hr}$ after iv administration of $40 \mathrm{mg}$ of amoxicillin $/ \mathrm{kg}$ of body weight were determined in nine rats by standard methods [8] with an inoculum of $10^{6} \mathrm{~S}$. intermedius. Subcultures were performed on penicillinase-containing blood agar (Bactopenase ${ }^{\circledast} ; \times 10^{6}$ IU/liter; Difco Laboratories, Detroit). The serum inhibitory titer was the highest dilution of serum inhibiting visible bacterial growth, and the serum bactericidal titer was the highest dilution of serum providing $99.9 \%$ killing of the original inoculum after incubation for $18 \mathrm{hr}$.

In vitro adherence assay. With a previously described in vitro assay system of platelet-fibrin matrices [2] simulating nonbacterial thrombotic endocarditis, we determined (l) the influence of amoxicillin on the in vitro adherence of $S$. intermedius to these matrices and (2) the influence of amoxicillin on the subsequent detachment of the adherent bacteria during prolonged exposure to the antibiotic. $S$. intermedius organisms grown overnight in brainheart infusion broth (Difco) were suspended in PBS supplemented with $25 \mu \mathrm{g}$ of amoxicillin (Beecham Research Laboratories, Bern, Switzerland)/ml, giving a final concentration of $10^{4} \mathrm{cfu} / \mathrm{ml}$. Controls were suspended in PBS alone. These suspensions were immediately poured on platelet-fibrin matrices $[2,3]$ in petri dishes and incubated for $5 \mathrm{~min}$ at $37 \mathrm{C}$ in a shaking incubator at $120 \mathrm{rpm}$. The supernatant was removed, and the matrices were washed two times for $5 \mathrm{~min}$ each with amoxicillin solution or with PBS alone. The petri dishes were then divided into two groups, with each one comprising a control and an amoxcillin-treated subgroup. The first group was washed a third time for 5 min with PBS sup- plemented with $2,000 \mathrm{U}$ of penicillinase $/ \mathrm{ml}$ for inhibition of residual amoxicillin on the matrices. The total time of exposure to amoxicillin (or PBS) in this group (15 min) was chosen for simulation of the mean duration of bacteremia after iv challenge, during which inhibition of adherence has to occur if bacterial colonization of the damaged valves is to be prevented [1]. In the second group, the time of exposure to amoxicillin in the shaking incubator was prolonged up to $4 \mathrm{hr}$ for simulation of the time of exposure of the bacteria that attached to the valve, despite adherence inhibition after a single iv prophylactic dose of amoxicillin [3]. The matrices were washed every half hour for $15 \mathrm{~min}$ with amoxicillin solution (or PBS), and the supernatant was carefully recovered for plating and colony counts. At the end of the assay, the matrices were washed for 15 min with PBS containing penicillinase, and penicillinase-containing blood agar was poured over the matrices. The adherent colonies were counted after incubation for $48 \mathrm{hr}$. The percentage of adherent colonies for each sample was defined as the number of $\mathrm{cfu}$ adherent to the matrix $\times 100$ divided by the initial number of cfu in the inoculum. The results are expressed as the mean values of 36 determinations in each subgroup performed in three consecutive experiments.

Animal model. Production of endocarditis. Sterile aortic vegetations were produced in female Wistar rats (body weight, $180-200 \mathrm{~g}$ ) by placement of a polyethylene catheter through the aortic valve as previously described [3]. Twenty-four hours after catheterization, rats were injected iv with $0.5 \mathrm{ml}$ of various sizes of bacterial inocula from an overnight culture of $S$. intermedius diluted in $0.9 \% \mathrm{NaCl}$.

Course of endocarditis with or without amoxicillin prophylaxis. Thirty minutes before bacterial challenge, groups of 40 rats were injected iv with either $40 \mathrm{mg}$ of amoxicillin $/ \mathrm{kg}$ of body weight ( 20 test rats) or $0.9 \% \mathrm{NaCl}$ (20 control rats). This dose of amoxicillin was chosen because at $30 \mathrm{~min}$ after iv injection in rats it produces peak serum levels similar to those in humans $2 \mathrm{hr}$ after an oral dose of 3 $\mathrm{g}$ [3], which has been advocated for prophylaxis in humans [9]. In some experiments, one or two identical subsequent doses of amoxicillin were given 6 and $12 \mathrm{hr}$ after the first dose. For investigation in vivo of the effect of amoxicillin on the adherence of $S$. intermedius on damaged aortic valves, one-half of the rats of the same experiment were killed early (10 min or $1,2,6$, or $12 \mathrm{hr}$ ), and the other half were killed three days after bacterial challenge. This pro- 
cedure permitted for each experiment a valuable correlation between early bacteriologic results and the subsequent development of endocarditis in both amoxicillin-treated and control rats.

Killing was performed as previously described [3, 71. All cultures of blood and of valve homogenates were performed on penicillinase-containing blood agar. In the groups killed early after bacterial challenge (i.e., at $10 \mathrm{~min}$ or $1,2,6$, or $12 \mathrm{hr}$ ), the valves were rinsed in $5 \mathrm{ml}$ of $0.9 \% \mathrm{NaCl}$ before homogenization for elimination of nonadherent bacteria. The total amount of homogenate was then plated for recovery of all adherent bacteria. Because of the small number of bacteria detected with early killing, the results were expressed as the number of bacteria recovered per valve. In animals killed three days after bacterial challenge, $0.1 \mathrm{ml}$ of appropriate dilutions of valve homogenates was plated for colony counts, and the results were expressed in $\log \mathrm{cfu} / \mathrm{g}$ of valve. Bacterial endocarditis was defined by positive cultures of valves.

Inactivation of amoxicillin with penicillinase in rats given antibiotic prophylaxis. In additional experiments two-thirds of the rats were given amoxicillin, and one-third served as controls. Thirty minutes after bacterial challenge with $10^{5} \mathrm{~S}$. intermedius, half of the amoxicillin-treated rats as well the control rats were given $0.5 \mathrm{ml}$ of iv penicillinase (Bactopenase; $5 \times 10^{5} \mathrm{IU} / \mathrm{ml}$ ). Ten minutes after iv injection of this amount of penicillinase, no detectable amoxicillin activity could be measured in the serum of rats. If prevention of valvular colonization due to the inhibition of bacterial adherence was the main mechanism responsible for the prevention of endocarditis, then penicillinase inactivation of the remaining antibiotic activity in the blood at the end of the bacteremic phase should not abolish successful prophylaxis. It has been previously established that $30 \mathrm{~min}$ after bacterial challenge with either $10^{5}$ or $10^{6} \mathrm{~S}$. intermedius, no circulating bacteria can be detected [1].

Statistical evaluation. The $\chi^{2}$ test with Yates's correction, the Wilcoxon rank sum test, and Student's unpaired $t$ test were used for statistical comparisons.

\section{Results}

Serum inhibitory and bactericidal titers against $S$. intermedius. The mean serum inhibitory titer 30 min, $2 \mathrm{hr}$, and $4 \mathrm{hr}$ after iv injection of amoxicillin was $1: 32,1: 8$, and 1:2, respectively. At $6 \mathrm{hr}$ no se- rum inhibitory activity was detectable. No serum bactericidal activity could be detected at any time.

Influence of amoxicillin on in vitro adherence of $S$. intermedius to platelet-fibrin matrices and on their subsequent detachment. When incubation in vitro with $25 \mu \mathrm{g}$ of amoxicillin $/ \mathrm{ml}$ was for an interval simulating the duration of bacteremia in vivo $(15 \mathrm{~min}$ [1]), the percentage (mean \pm SD value of 36 determinations) of $S$. intermedius adherent to plateletfibrin matrices was reduced from $0.13 \% \pm 0.08 \%$ in controls to $0.09 \% \pm 0.05 \%$ in amoxicillin-treated bacteria, a reduction of $30 \%(P<.05)$.

When the in vitro adherent bacteria were washed during $4 \mathrm{hr}$ with $25 \mu \mathrm{g}$ of amoxicillin/ml or with PBS (simulating the time of exposure of bacteria in vivo to amoxicillin levels in rats after one prophylactic dose), the percentage (mean \pm SD value of 36 determinations) of adherent $S$. intermedius decreased to the same extent in the control group (from $0.13 \%$ $\pm 0.08 \%$ to $0.08 \% \pm 0.05 \%$, a reduction of $38 \%$ ) and in the amoxicillin-treated group (from $0.09 \%$ $\pm 0.05 \%$ to $0.06 \% \pm 0.06 \%$, a reduction of $33 \%$ ). This reduction was due to detachment of the adherent bacteria, as shown by their recovery on culture of the washing medium. Control experiments with tryptic soy broth (Gibco Europe, Daisley, Scotland) instead of PBS as the washing medium (a medium that may have provided more growth factors than PBS alone) showed similar results (data not shown).

Bacterial colonization of damaged valves and subsequent development of endocarditis after iv injection of various inoculum sizes of S. intermedius. Experiments with $10^{4} \mathrm{~S}$. intermedius (control rats only). When rats were killed $10 \mathrm{~min}$ after bacterial challenge, four of five valvular homogenates yielded $S$. intermedius (1-5 cfu per valve). All cultures of blood were sterile at this time. In rats killed 1 and $2 \mathrm{hr}$ after bacterial challenge, four of nine and three of eight valvular homogenates, respectively, still yielded $S$. intermedius (1-8 cfu per valve). After 6 $\mathrm{hr}$, however, $S$. intermedius was no longer detectable on the valves of all seven rats killed at this time. When animals were killed three days after bacterial challenge, only two $(9.5 \%)$ of 21 rats had developed bacterial endocarditis. Thus it was common for a few bacteria to adhere early to the damaged valves after injection with $10^{4} \mathrm{~S}$. intermedius, but these bacteria had spontaneously disappeared within the next few hours, and almost all animals had sterile vegetations at three days.

Experiments with $10^{5} \mathrm{~S}$. intermedius. Although all animals had detectable $S$. intermedius on their 
aortic valves $10 \mathrm{~min}$ after bacterial inoculation, the number of streptococcal colonies attached to the valves of amoxicillin-treated animals (median, 8; range, 1-14) was slightly but significantly lower than in controls (median, 13 ; range, $8-50 ; P<.05$ by Wilcoxon rank sum test; figure 1). The reduction in number of cfu per valve was not due to different numbers of circulating bacteria because quantitative cultures of blood performed at the time of killing yielded similar numbers of bacteria: $12.6 \pm 9.6 \mathrm{cfu}$ / $\mathrm{ml}$ in control rats versus $16 \pm 27 \mathrm{cfu} / \mathrm{ml}$ in amoxicillin-treated rats. Furthermore, killing could not account for this reduction because exposure to the antibiotic was very brief and there was no detectable serum bactericidal activity at this time. Therefore at this time of death (10 min), antibiotic-mediated inhibition of bacterial adherence was a likely mechanism involved in the reduction of streptococcal numbers on the heart valves of amoxicillin-treated rats when compared with the bacterial numbers in controls.

One hour after bacterial challenge a slight decrease in number of cfu per valve was detected in both groups of rats compared with the number of cfu per valve in animals killed $10 \mathrm{~min}$ after bacterial challenge. However, when animals were killed 2 or $6 \mathrm{hr}$ after bacterial challenge, the number of cfu per valve in control rats had increased by 2.5 - and 10-fold, respectively, compared with the number in control animals killed at $1 \mathrm{hr}$, a finding demonstrating that the adherent bacteria had started to multiply. In contrast, the valvular homogenates of amoxicillintreated rats showed a further reduction in the number of cfu per valve in animals killed at 2 or $6 \mathrm{hr}$, and five of nine valves were completely sterile at the latter time.

When rats were killed three days after bacterial challenge, $32(89 \%)$ of 36 control animals had developed endocarditis due to $S$. intermedius, a result demonstrating that $10^{5} \mathrm{~S}$. intermedius used as an inoculum for iv bacterial challenge were sufficient to produce endocarditis in $90 \%$ of the rats. In contrast, in the amoxicillin-treated rats, endocarditis was present in only eight $(23 \%)$ of 34 rats $\left(P<10^{-4}\right)$, a result demonstrating the successful prophylaxis afforded by amoxicillin after challenge with the $90 \%$ infectious dose.

Effect of amoxicillin inactivation by penicillinase injected 30 min after bacterial challenge with $10^{5}$ $S$. intermedius. Penicillinase treatment $30 \mathrm{~min}$ after bacterial challenge completely abolished the prophylactic effect of amoxicillin. When animals were killed three days after bacterial challenge, only $11(36 \%)$ of 30 rats given amoxicillin alone had developed endocarditis compared with $21(84 \%)$ of 25 rats that had received penicillinase after amoxicillin prophylaxis $(P<.01)$, an incidence similar to that in control rats operated on at the same time (18 [90\%] of 20). These results suggested that some antibac-
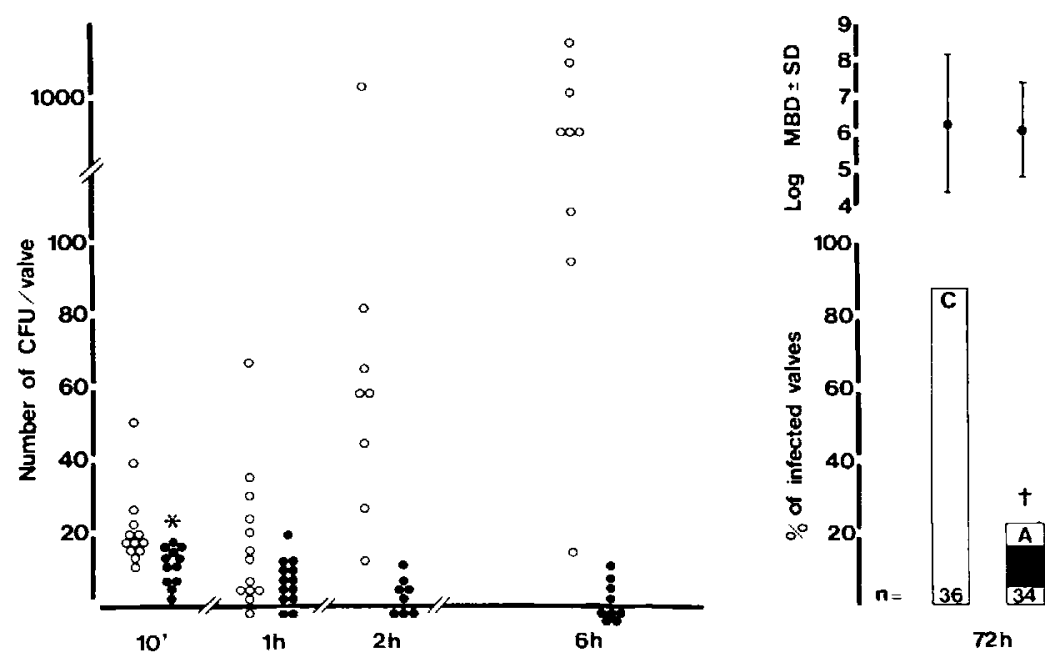

Figure 1. Natural history of endocarditis due to $S$. intermedius early after iv challenge with $10^{5} \mathrm{cfu}$. Left, absolute numbers of bacteria cultured from the damaged valves during the early course of endocarditis. Each point represents the number of bacteria on the valve of one single rat: controls $(O)$ and amoxicillin-treated rats (๑). Right, the incidence of endocarditis in paired control $(C)$ and amoxicillin-treated $(A)$ rats three days after iv challenge with $10^{5} \mathrm{~S}$. intermedius. The numbers at the bottom of each column are the number of rats in each group. In the upper part are given the mean \pm SD (bars) bacterial densities (MBD) recovered from infected valves (expressed as $\log \mathrm{cfu} / \mathrm{g}$ of valve). An asterisk indicates $P<.05$ compared with control rats by Wilcoxon rank sum test. A dagger indicates $P<.0001$ compared with controls by $\chi^{2}$ test with Yates's correction. 
terial activity in the serum was necessary for successful prophylaxis even after the end of the bacteremic phase after the iv challenge.

Experiments with $10^{6} \mathrm{~S}$. intermedius. Early after bacterial challenge with an inoculum 10 times greater than the $90 \%$ infectious dose, the valves were colonized with $\sim 10$ times more bacteria than the valves in animals challenged with an inoculum of $10^{5} \mathrm{~S}$. intermedius (figure 2). Ten minutes after bacterial challenge the amoxicillin-treated group showed a slight but nonsignificant reduction in the number of cfu per valve compared with the control group. Quantitative cultures of blood at this time of killing yielded $32 \pm 25 \mathrm{cfu} / \mathrm{ml}$ of blood in controls versus $23 \pm 11 \mathrm{cfu} / \mathrm{ml}$ in amoxicillin-treated rats $(P>.1)$. In rats killed $1 \mathrm{hr}$ after bacterial challenge, the number of cfu per valve was slightly reduced in both groups of rats compared with bacterial numbers recovered at $10 \mathrm{~min}$, and cultures of blood were sterile. At 2, 6, and $12 \mathrm{hr}$ after challenge a rapid bacterial growth was observed on cultures of the valves in control rats. In contrast, in the amoxicillin-treated group a further reduction in the numbers of cfu per valve was observed up to $6 \mathrm{hr}$. This reduction corresponded approximately to the interval that serum inhibitory activity was measurable after amoxicillin prophylaxis. However, unlike the valves in the experiments with an inoculum of $10^{5} \mathrm{~S}$. intermedius, eight of nine valves were still infected at this time. As a result, when animals were :.lled after $12 \mathrm{hr}$, when there was no serum inhibitory activity detectable, 13 of 14 amoxicillin-treated rats had a 100 -fold increase in bacterial numbers, and at three days $60(92 \%)$ of 65 control animals and $63(91 \%)$ of 68 amoxicillin- treated animals had developed full-blown endocarditis due to $S$. intermedius. Therefore the reduction in number of cfu per valve observed during the first $6 \mathrm{hr}$ was not sufficient for prevention of bacterial growth to resume once serum inhibitory activity was no longer detectable.

Effect of multiple doses of amoxicillin in rats chatlenged with $10^{6} \mathrm{~S}$. intermedius. In a further investigation of whether prolonged bacteriostatic activity after amoxicillin prophylaxis was a likely mechanism of protection against the development of endocarditis, experiments were performed in which amoxicillin-treated rats challenged with $10^{6} \mathrm{~S}$. intermedius (an inoculum 10 times greater than the $90 \%$ infectious dose that overcame successful single-dose amoxicillin prophylaxis) were given none, one, or two subsequent doses of amoxicillin at 6-hr intervals. In these experiments the incidence of endocarditis was $90 \%$ (38 of 42 ) in rats given a single amoxicillin prophylactic dose, 69\% (11 of 16$)$ in rats given one subsequent dose $6 \mathrm{hr}$ thereafter $(P>.1)$, and $25 \%$ (6 of 24) in rats given two subsequent doses at 6 and $12 \mathrm{hr}$ after bacterial challenge $\left(P<10^{-4}\right.$ compared with the other two groups of rats). Therefore, providing serum inhibitory levels of amoxicillin during an 18-hr period extended the prophylactic efficacy of amoxicillin to a bacterial inoculum 10 times greater than the $90 \%$ infectious dose.

\section{Discussion}

Several recent studies performed both in vitro and in vivo [1-4] have provided indirect evidence that inhibition of bacterial adherence might be a mecha-
Figure 2. Natural history of endocarditis due to $S$. intermedius after iv challenge with $10^{6} \mathrm{cfu}$. Left, mean \pm SD (bars) numbers of bacteria cultured from the damaged valves during the early course of endocarditis: controls $(O)$ and amoxicillin-treated rats (๑). The numbers next to each point are the number of rats at each interval. Right, the incidence of endocarditis in paired control $(C)$ and amoxicillin-treated $(A)$ rats three days after iv challenge with $10^{6} \mathrm{~S}$. intermedius. The numbers at the bottom of each column are the number of rats in each group. In the upper part are given the mean $\pm \mathrm{SD}$ (bars) bacterial densities (MBD) recovered from the infected valves (expressed as $\log \mathrm{cfu} / \mathrm{g}$ of valve).
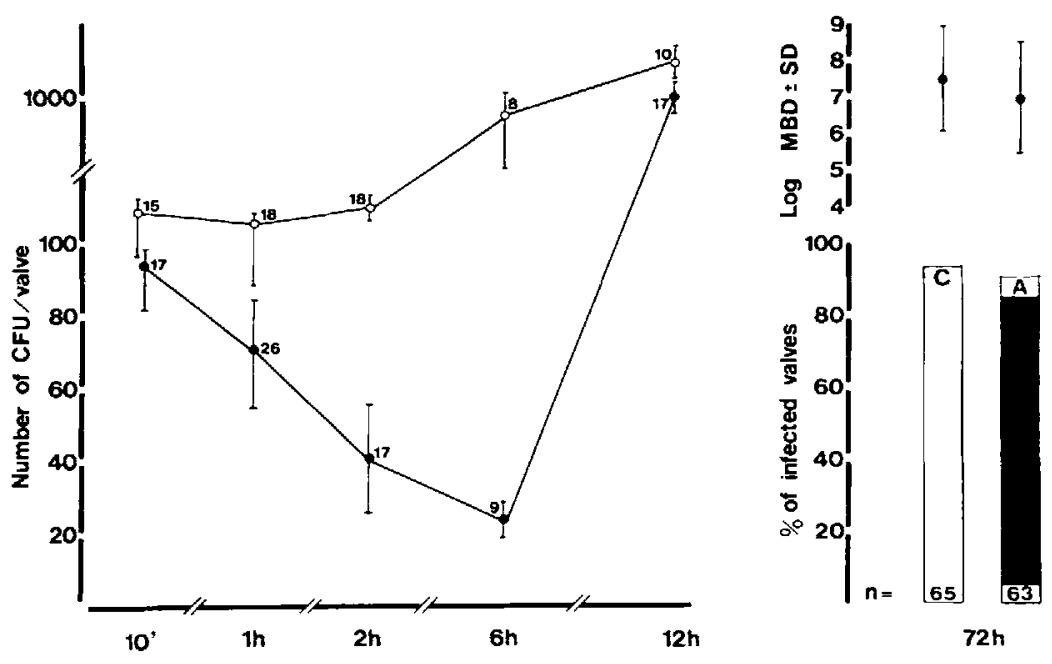
nism by which antibiotics prevent bacterial endocarditis in the absence of bacterial killing. In the present experiments with a streptococcal strain $(S$. intermedius) tolerant to the killing effect of amoxicillin, we have also observed that amoxicillin-treated bacteria were less able than controls to stick to platelet-fibrin matrices in vitro and to colonize damaged valves in rats with catheter-induced vegetations. It is likely, however, that this early reduction in the valvular colonization observed in treated rats at the end of the bacteremia could not entirely explain the successful protection afforded by amoxicillin, for at least two reasons. First, in rats challenged with $10^{5} \mathrm{cfu}$ of $S$. intermedius (i.e., the minimal inoculum infecting $90 \%$ of control rats), although the average number of cfu per valve 10 and $60 \mathrm{~min}$ after iv challenge was slightly decreased after amoxicillin prophylaxis, there was a striking overlap in the number of bacteria present on the valves of amoxicillin-treated and control rats. In contrast, the reduction in the incidence of endocarditis conferred by amoxicillin in rats killed at three days was $74 \%$ compared with the incidence in control rats. Second, the inactivation of amoxicillin by penicillinase $30 \mathrm{~min}$ after bacterial challenge completely abolished its prophylactic efficacy. If the decrease in early valvular colonization due to the inhibition of bacterial adherence by amoxicillin were to play a major role in the prevention of bacterial endocarditis, suppression of the antibiotic activity in serum after the end of the bacteremic phase should not have abolished the prophylactic effect of amoxicillin. It appears therefore that for conferring protection, amoxicillin had to be present in rat serum after the end of the bacteremia, i.e., after the circulating microorganisms had attached to the cardiac vegetations.

During the first $6 \mathrm{hr}$ after the iv challenge with both $10^{5}$ and $10^{6} \mathrm{~S}$. intermedius (i.e., until the serum levels of amoxicillin became undetectable), rates of growth of bacteria recovered from the valves of amoxicillin-treated animals and controls were strikingly different. In control rats, bacterial multiplication on the damaged valves could already be detected $2 \mathrm{hr}$ after bacterial challenge, and a 10 -fold increase was observed after $6 \mathrm{hr}$. In contrast, the number of $\mathrm{cfu}$ on the valves of amoxicillin-treated rats decreased progressively during the 6-hr interval after iv challenge. During this period, the bacteria $\left(10^{5} \mathrm{~S}\right.$. intermedius) disappeared from the damaged valves, but this was not enough time for complete clearance after challenge with $10^{6} \mathrm{~S}$. intermedius.
Several possible mechanisms might have been responsible for the decrease in the number of cfu on the valves of animals given prophylactic amoxicillin. First, the adherent bacteria might have been killed by amoxicillin. However, we have previously shown in vitro that sustained amoxicillin concentrations simulating peak serum levels did not kill $10^{6}$ $S$. intermedius over a 24-hr incubation period [3]. Similarly, exposure of $10^{3}$ and $10^{2} S$. intermedius (simulating bacterial numbers present on vegetations early after bacterial challenge) to peak concentrations of amoxicillin for $24 \mathrm{hr}$ did not result in significant bacterial killing (data not shown) and thus rendered unlikely the possibility that small bacterial inocula could be killed faster than large inocula. Moreover, in vivo serum bactericidal activity was not detectable in rats at the time of bacterial challenge, i.e., at the time of peak amoxicillin level. Thus, although the presence of active amoxicillin in serum for several hours after bacterial challenge was necessary for successful endocarditis prophylaxis, mechanisms other than mere killing by amoxicillin appeared to be responsible for the reduction in bacterial numbers on the valves.

A second possible mechanism for diminished bacterial numbers during antibiotic exposure might be related to amoxicillin-mediated detachment of bacteria from the vegetations. Amoxicillin slightly but clearly interfered with the in vitro and in vivo sticking of $S$. intermedius to platelet-fibrin structures. It is conceivable that the drug subsequently weakened the attachment of adherent bacteria to the vegetations. If this hypothesis were true, inhibition by amoxicillin of adherence mechanisms would have had two manifestations: $(I)$ the failure of organisms to attach initially and (2) the detachment of already adherent bacteria. However, the latter hypothesis of antibiotic-mediated detachment was not supported by in vitro experiments, which showed that prolonged exposure to and washing with amoxicillin of the platelet-fibrin matrices did not increase the detachment of $S$. intermedius over that seen with PBS washes. Similarly, Lowy et al. [4] did not observe increased detachment of streptococci adherent to platelet-fibrin matrices on exposure to inhibitory concentrations of penicillin. The detachment hypothesis was not supported by in vivo observations either, which showed that in untreated rats killed early after bacterial challenge there was a spontaneous trend toward the disappearance of bacteria from the colonized valves, even in the absence of antibi- 
otic prophylaxis. This finding was most striking in the experiments with $10^{4} \mathrm{~S}$. intermedius, in which the valves were colonized with small numbers of bacteria early after iv challenge but were sterile three days later. Similarly, when 10 and 100 times larger inocula were injected iv, which resulted in attachment of 10-100 times more bacteria on the valves, the number of adherent bacteria decreased to the same extent in the control and amoxicillin-treated rats during the first hour after bacterial challenge, before bacterial growth started in controls. Thus even in the absence of antibiotic, bacteria attached to the damaged valves showed a natural tendency toward disappearance. Therefore, the in vivo and in vitro observations did not support the hypothesis that the inhibition of attachment, the promotion of detachment, or both fully accounted for successful antibiotic prophylaxis.

Successful prophylaxis against $S$. intermedius endocarditis afforded by amoxicillin in the present experiments was apparently not conferred by bacterial killing mechanisms due to amoxicillin alone, or by mechanisms related to inhibition of adherence or promotion of detachment. Because the presence of bacteriostatic concentrations of amoxicillin for several hours after the bacteremic phase was crucial for prophylaxis, the mere inhibition of bacterial growth may be responsible for the successful prophylaxis in allowing the adherent bacteria to disappear from the valves. Six hours of bacterial growth inhibition provided by one dose of amoxicillin permitted bacterial clearance and successful prophylaxis in animals challenged with $10^{5} \mathrm{~S}$. intermedius, and two subsequent doses (inhibiting bacterial growth during an 18-hr period) afforded ef fective protection in animals challenged with $10^{6} \mathrm{~S}$. intermedius. Whether the bacterial clearance of resting organisms was solely due to hemodynamic forces, or whether it was mediated by host defense factors alone [10-12] or promoted by amoxicillin remains to be determined [5, 13].

In conclusion, the present experiments suggest that in the absence of bacterial killing, growth inhibition may be an important mechanism of successful antibiotic prophylaxis of endocarditis in allowing the bacteria to be cleared from the damaged valves. When large inocula are used, prolonged administration of inhibitory concentrations of antibiotics might circumvent the limited efficacy of antibiotics in preventing endocarditis.

\section{References}

1. Bernard JP, Francioli P, Glauser MP. Vancomycin prophylaxis of experimental Streptococcus sanguis. Inhibition of bacterial adherence rather than bacterial killing. J Clin Invest 1981;68:1113-6

2. Scheld WM, Zak O, Vosbeck K, Sande MA. Bacterial adhesion in the pathogenesis of infective endocarditis: effect of subinhibitory antibiotic concentrations on streptococcal adhesion in vitro and the development of endocarditis in rabbits. J Clin Invest 1981;68:1381-4

3. Glauser MP, Bernard JP, Moreillon P, Francioli P. Successful single-dose amoxicillin prophylaxis against experimental streptococcal endocarditis: evidence for two mechanisms of protection. J Infect Dis 1983;147:568-75

4. Lowy FD, Chang DS, Neuhaus EG, Horne DS, Tomasz A, Steigbigel NH. Effect of penicillin on the adherence of Streptococcus sanguis in vitro and in the rabbit model of endocarditis. J Clin Invest 1983;71:668-75

5. McDonald PJ, Wetherall BL, Pruul H. Postantibiotic leukocyte enhancement: increased susceptibility of bacteria pretreated with antibiotics to activity of leukocytes. Rev Infect Dis 1981;3:38-44

6. Arnold SB, Valone JA, Askenase PW, Kashgarian M, Freedman LR. Diffuse glomerulonephritis in rabbits with Streptococcus viridans endocarditis. Lab Invest 1975;32:681-9

7. Héraief E, Glauser MP, Freedman LR. Natural history of aortic valve endocarditis in rats. Infect Immun 1982;37: $127-31$

8. Sabath LD, Anhalt JP. Assay of antimicrobics. In: Lennette EH, Balows A, Hausler WJ Jr, Truant JP, eds. Manual of clinical microbiology. 3rd ed. Washington, DC: American Society for Microbiology, 1980:485-90

9. The antibiotic prophylaxis of infective endocarditis. Report of a Working Party of the British Society for Antimicrobial Chemotherapy. Lancet 1982;2:1323-6

10. Francioli PB, Freedman LR. Streptococcal infection of endocardial and other intravascular vegetations in rabbits: natural history and effect of dexamethasone. Infect Immun 1979;24:483-91

11. Meddens MJ, Thompson J, Eulderink F, Bauer WC, Mattic $\mathrm{H}$, Van Furth R. Role of granulocytes in experimental Streptococcus sanguis endocarditis. Infect Immun 1982;36: 325-32

12. Meddens MJ, Thompson J, Leijh PC, Van Furth R. Role of granulocytes in the induction of an experimental endocarditis with a dextran-producing Sireptococcus sanguis and its dextran-negative mutant. Br J Exp Pathol 1984; 65: 257-65

13. Horne D, Tomasz A. Hypersusceptibility of penicillin-treated group B streptococci to bactericidal activity of human polymorphonuclear leukocytes. Antimicrob Agents Chemother $1981 ; 19: 745-53$ 